\title{
Trends in Contraceptive Choices among Women Attending the Family Planning Clinic in a Nigerian Tertiary Hospital in Makurdi, Nigeria
}

\section{Samuel K Hembah-Hilekaan ${ }^{1 *}$, Augustine O Ojabo ${ }^{1}$, Audu Onyemocho ${ }^{2}$, Peter E Onche ${ }^{1}$, Micheal T Maanongun ${ }^{1}$, Daniel O Hilary ${ }^{1}$ and Celina Ishell ${ }^{3}$}

${ }^{1}$ Department of Obstetrics and Gynecology, Benue State University Teaching Hospital, Makurdi, Nigeria

${ }^{2}$ Department of Epidemiology and Community Health, Benue State University Teaching Hospital, Makurdi, Nigeria

${ }^{3}$ Department of Nursing, Benue State University Teaching Hospital, Makurdi, Nigeria

*Corresponding author: Samuel K Hembah-Hilekaan, Department of Obstetrics and Gynecology, Benue State University Teaching Hospital, Makurdi, Nigeria, Tel: +234-8035722335; E-mail: hemhilsk@yahoo.com

Received date: March 15, 2018; Accepted date: March 20, 2018; Published date: March 27, 2018.

Copyright: (C) 2018 Hembah-Hilekaan SK, et al. This is an open-access article distributed under the terms of the Creative Commons Attribution License, which permits unrestricted use, distribution, and reproduction in any medium, provided the original author and source are credited.

Citation: Hembah-Hilekaan SK, Augustine OO, Onyemocho A, Onche PE, Maanongun MT, et al. (2018) Trends in Contraceptive Choices among Women Attending the Family Planning Clinic in a Nigerian Tertiary Hospital in Makurdi, Nigeria. J Contracept Stud Vol.3 No.2:11

\section{Abstract}

Aims/Objectives: To examine the socio-demographic characteristics and the trends in contraceptive choices including counseling of clients, using the family planning clinic of the newly established Benue State University Teaching Hospital, Makurdi.

Study design: A retrospective cross-sectional study.

Setting: Benue State University Teaching Hospital, Makurdi, Nigeria.

Subjects: New subjects attending the family planning clinic.

Main outcome measures: Contraceptive choices and trend including the social demographic variables of subjects over the study period.

Results: During the 3 year study period, 807 clients were seen at the family planning clinic. The overall contraceptive prevalence rate was $39.0 \%$ with a rising trend from $17.7 \%$ in the first year to $50.8 \%$ in the last year. Majority of the clients chose implants 467 (57.9\%), 20.4\% condoms, $12.8 \%$ IUCDs, $9.9 \%$ injectable, $5.3 \%$ combined pills and $0.1 \%$ bilateral tubal ligation. Adolescents constituted only $16 \%$ of the population studied.

Conclusions: There was a rising trend in contraceptive use with the implant as the most common contraceptive used in our center followed by the condom.

Keywords: Family planning; Trends; Contraceptive choices; Makurdi; Nigeria

\section{Introduction}

Unexpected or unplanned pregnancy poses a major public health challenge for women of reproductive age, especially in developing countries [1]. Nigeria, with a population of close to 160 million, an expected national growth rate of $3.2 \%$, and a total fertility rate of 5.7 and 6.3 in urban and rural areas, respectively, has an expected maternal death rate of 545 per 100,000 live births and 6.8 million pregnancies annually, of which $16 \%$ end in spontaneous miscarriage and $11 \%$ in induced abortion [2,3]. About 30 million women are in the reproductive age group and contraceptive prevalence rate (any method) is only $15 \%$ [2].

An estimated 123 million couples, mainly in developing countries do not use contraceptives despite wanting to space or limit their childbearing [4]. The use of modern family planning methods is an effective tool to control the rising population in Nigeria. The most recent Nigeria Demographic and Health Survey (2013) put the overall contraceptive prevalence rate among married women aged $15-49$ years using modern methods at $9.8 \%$ against $9.7 \%$ in the 2008 report [5]. Non usage of contraceptives by reproductive age women, who engage in sexual activity, can result in unwanted/ unplanned pregnancy with its attendant problems such as induced/unsafe abortion, post abortion sepsis and maternal death [6]. It has been documented that 600,000 unsafe abortions occur annually in Nigeria [6]. Some of the late complications of abortion are pelvic pain, dyspareunia, ectopic pregnancy and infertility. Other problems associated with non-usage of contraceptives include the rampart food scarcity, population explosion, the HIV pandemic and other reproductive health infections and the socioeconomic development challenges seen, especially in the developing countries like Nigeria.

Factors responsible for contraceptive choices vary from place to place even within the same country. Some of these factors include social, economic and low level of awareness 
and education. Family planning in many parts of Nigeria is influenced by cultural and religious beliefs [7]. The low contraceptive prevalence has been attributed to poverty, ignorance, low educational level, and desire for large family size, poor access to contraceptive services, community pressure, male or husband dominance, and religious beliefs [7].

This study reviewed 3 years records of data of clients attending the family planning clinic of Benue State University Teaching Hospital, Makurdi in order to examine the sociodemographic characteristics and the trends in contraceptive choices including counseling of clients.

\section{Materials and Methods}

\section{Location}

This study was carried out from September, 2012 to August, 2015 at the newly established Benue State University Teaching Hospital located in Makurdi, North Central Nigeria.

\section{Study design and population}

A retrospective cross sectional study design with convenient non-probability sampling technique was used for this study. All family clinic attendees enrolled for any form of family planning between September, 2012 and August, 2015 were included in the study. Those whose hospital records were incomplete were excluded from the study. The study was carried out over a three year period (from September, 2012 and August, 2015, both years inclusive). The contraceptives offered at the Centre during the study period included oral pills, injectable methods (Noristerat and Depo Provera), copper T intrauterine device, implants (although Merina IUD was not available at the Centre during the study period) and bilateral tubal ligation including male sterilization, and male and female condoms.

\section{Data collection}

A standard pretested pro forma was used for data collection. Data sources were medical record files, family planning unit records, Obstetrics and Gynecology theatre records. Information obtained include: socio-demographic characteristics of the women such as age, parity, educational status including family planning choices, and information on whether the client was counseled were collected. Ethical clearance was obtained from the institutional review board before the commencement of the study.

\section{Data analysis}

Data that were extracted from the data sources were entered into predesigned software in Statistical Packages for Social Sciences (SPSS) version 23 (IBM corp Released 2015 IBM SPSS statistics for windows, version 19.0, Armonk, NY: IBM Corp) and analyzed. Frequency tables, charts, mean and standard deviation were used to summarize the independent variables of interest. The main outcome of the study was compared with the independent variables of interest and Pearson chi- square $(\chi 2)$ test was used for test of association between the independent variables and the main outcome of the study, with statistical significance set at $p$ - value of $5 \%$. Linear relationship between the predictor variable and the outcome (criterion variable) was further performed for selected independent predictors that have significant chisquare, using multiple logistic regression models by controlling for possible confounders.

\section{Results}

During the period of this study, 807 clients attending the family planning clinic were analyzed. Within the same period under review there were 2071 ANC attendees recorded, giving a contraceptive prevalence rate of $39.0 \%$. Although 807 clients were studied, some of them practiced two methods of contraception at the same time probably due to the fear of failure of one and others for infections, resulting in a total usage of 859. The contraceptive preference rate was found to be rising over the three year period from $17.7 \%$ in the first year to $50.8 \%$ in the last year (Figure 1).

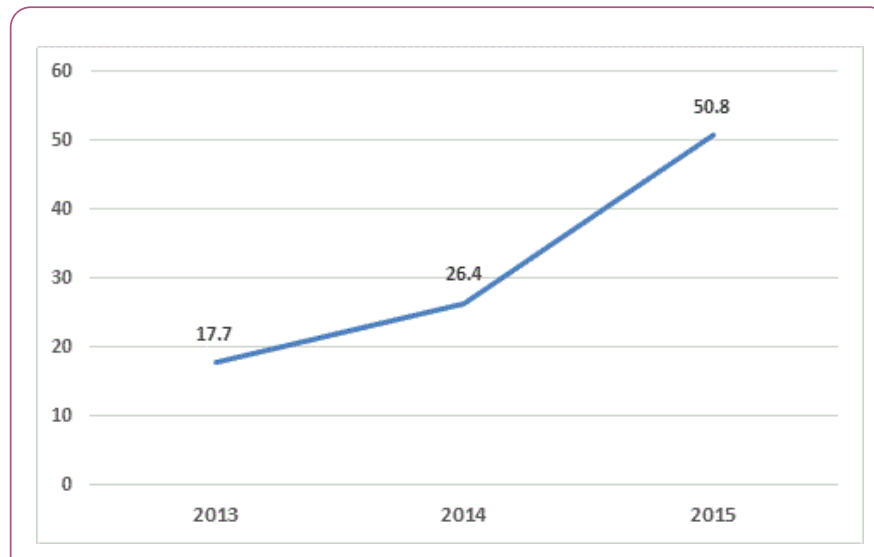

Figure 1 Trend of contraceptive use (September 2012August 2015).

Table 1 shows that the ages range of the participants was $13-50$ years, with a mean of $29.7( \pm 5.8$ ) years. The parity of the participants ranged from $0-14$ with an average of $3( \pm 1.8)$. Majority $(94.1 \%)$ of the contraceptive users were in the age bracket $20-40$ years. Only $1.6 \%$ of the clients were less than 20 years of age.

The parity distribution of the attendees showed that majority 320 (39.7\%) had 1-2 deliveries, 296 (36.7\%) had 2-4 while 135 (16.7\%) were grand multiparous women. Nulliparous clients made up only $56(6.9 \%)$ of the total participants. The educational status of the family planning clinic attendees revealed a marked shift of 659 (81.7\%) in favor of those who had secondary and tertiary level education. Those with primary level education were 118 (14.6\%), while 
only 30 (3.7\%) of the study group with no formal education were using modern contraceptive methods.

Table 1 Socio-demographic Characteristics of Respondents $(n=807)$.

\begin{tabular}{|c|c|c|}
\hline Age (years) & Frequency & Percent \\
\hline $13-19$ & 13 & 1.6 \\
\hline $20-26$ & 218 & 27.0 \\
\hline $27-33$ & 377 & 46.7 \\
\hline $34-40$ & 165 & 20.4 \\
\hline $41-47$ & 27 & 3.3 \\
\hline$\geq 48$ & 7 & 0.9 \\
\hline \multicolumn{3}{|l|}{ Parity } \\
\hline 0 & 56 & 6.9 \\
\hline $1-2$ & 320 & 39.7 \\
\hline $2-4$ & 296 & 36.7 \\
\hline$\geq 5$ & 135 & 16.7 \\
\hline \multicolumn{3}{|l|}{ Educational status } \\
\hline No formal education & 30 & 3.7 \\
\hline Primary & 118 & 14.6 \\
\hline Secondary & 434 & 53.8 \\
\hline Tertiary & 225 & 27.9 \\
\hline
\end{tabular}

On counseling (Figure 1), there was information in the records that majority $63.1 \%$ of the clients were counseled while $36.9 \%$ were not. It was also found that, $35.1 \%$ of the clients were new contraceptive users, $60.3 \%$ were continuing with their previous methods and $4.6 \%$ changed methods.

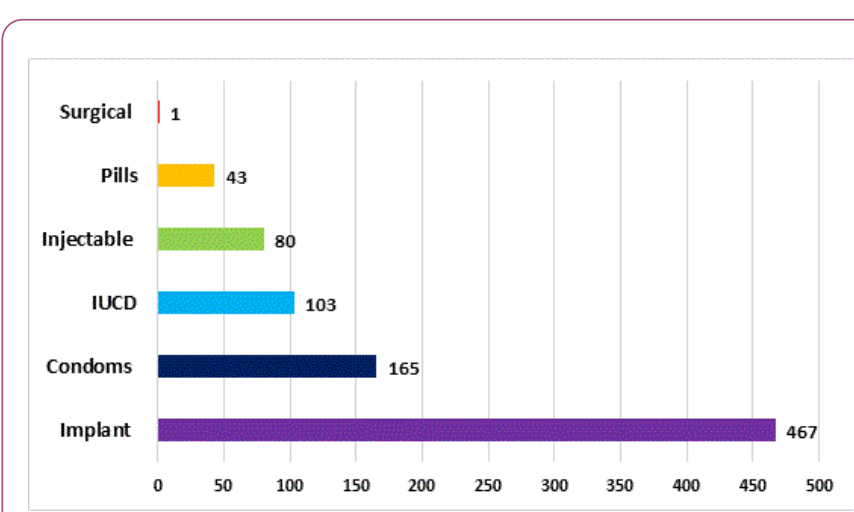

Figure 2 Types of contraception practiced by Clients.

Figure 2 shows that, the predominant method of contraceptive chosen was the implant (54.4\%), followed by male condoms (19.2\%), IUCD (12.0\%), injectable (Norististerone enanthate and DepoMedroxyprgesterone acetate-DMPA) (9.3\%), and combined oral contraceptive pills
(5.0\%). The least accepted method with only $1(0.1 \%)$ case was bilateral tubal ligation. No case of vasectomy was found among the contraceptive users.

Table $\mathbf{2}$ is a multivariate linear regression analysis of sociodemographic variables (predictors) to the type of contraception used (criterion variable). Using the enter method, a significant model for the different outcome variables emerged as follows; Injectable (F4, 147=351.007, $\mathrm{P}<0.0005$, and adjusted $\mathrm{R}$ square $=0.901)$. Of all the predictors (age, parity and educational status), only age and parity had a significant impact on the choice of contraceptive method. With reference to use of implant, age had higher impact (Beta=1.079) compared to parity (Beta=0.764). Concerning the use of condoms parity had higher impact (Beta=1.354) compared to age (Beta=0.912). For IUCD and Injectable the significant predictor is age, while for pills the significant predictor is the parity of the clients. The impact of educational status on uses of surgical contraceptive methods is higher than parity and age, but the relationship is not statistically significant $(p>0.05)$. The educational level of the respondents did not have a significant impact on the choice of contraceptive choices $(P>0.005)$. The source of information and referral to the family planning unit was mainly relatives/ friends and health personnel.

Table 2 Multiple Linear Regressions. 


\begin{tabular}{|c|c|c|c|c|c|c|}
\hline \multirow[t]{3}{*}{ Predictor Variable } & \multicolumn{6}{|c|}{ Dependent Variable: Choice of contraception } \\
\hline & Implant & Condom & IUCD & Injectable & Pills & Surgical \\
\hline & $\begin{array}{l}\text { Beta } \\
\text { (P-Value) }\end{array}$ & $\begin{array}{l}\text { Beta } \\
\text { (P-Value) }\end{array}$ & $\begin{array}{l}\text { Beta } \\
\text { (P-Value) }\end{array}$ & $\begin{array}{l}\text { Beta } \\
\text { (P-Value) }\end{array}$ & $\begin{array}{l}\text { Beta } \\
\text { (P-Value) }\end{array}$ & $\begin{array}{l}\text { Beta } \\
\text { (P-Value) }\end{array}$ \\
\hline Age (years ) & $1.079(0.000)^{*}$ & $0.912(0.000)^{*}$ & $0.941\left(0.002^{*}\right)$ & $1.057(0.030)^{*}$ & $0.983(0.583)$ & $0.815(0.180)$ \\
\hline Parity & $0.764(0.000)^{*}$ & $1.354(0.000)^{*}$ & $0.888(0.058)$ & $1.163(0.077)$ & $1.833(0.000)^{\star}$ & $1.314(0.645)$ \\
\hline Educational status & $1.166(0.132)$ & $0.896(0.383)$ & $0.929(0.617)$ & $0.858(0.375)$ & $1.006(0.979)$ & $1.468(0.755)$ \\
\hline
\end{tabular}

\section{Discussion}

Women who use modern methods of contraception are less likely to have unwanted and undesired pregnancies resulting in grand multiparty and unsafe and illegal abortions with all its dangerous complications. Contraceptives benefit the individual by limiting family size and the complications of grand multiparty and abortion while countries benefit by reduction in population. Despite the advances in health indicators in Nigeria, contraceptive services are still not universally available and even where they are; the utilization of such services is not optimal due to various reasons.

The contraceptive prevalence rate is related to the maternal mortality rate, and it has been shown that countries with a low prevalence of contraception have high maternal mortality rates [8]. The institutional contraceptive prevalence rate in this study was 39.0\%. whereas, the 2013 Nigerian Demographic and Health Survey put the use/unmet need for modern contraceptives among married women aged 15 to 49 years in Nigeria respectively at $9.8 / 16.1 \%$ overall, $16.9 / 14.9 \%$ in urban centers and $5.7 / 16.8 \%$ in rural areas [9]. There was a rising trend in the prevalence rate of contraceptive use from $17.7 \%$ in the first year to $50.8 \%$ in the last year during the study period. This may be due to an increasing demand for modern contraceptives among clients or improved availability in the newly established tertiary hospital.

The age range of the study participants was from 13 to 50 years with most $377(46.7 \%)$ of them in the age group of 27 and 33 years, while the least frequency $(0.95 \%)$ was in those equal or greater than 48 years which is consistent with declining reproductive capacity and hence the reduced need and low desire for contraception. This was followed by adolescents below 20 years of age who are likely to be in high need for contraceptives. The recorded low usage of $1.6 \%$ for modern contraceptives in our center among these adolescents, who are reported to be sexually active, and account for $60 \%$ of the 610,000 induced abortions in Nigeria [10], may call for urgent intervention by all concerned. Several reasons have been proffered for the low contraceptive use in this group from shyness, attitude of health workers to other factors that affect family planning such as ignorance, religion, traditional beliefs, and availability of services. Majority of the clients $(73.7 \%)$ were in the age range of 20 to 33 years representing the peak age of reproductive capacity and in most need for services. These findings are similar to those in Sokoto, Zaria and Port Harcourt $[4,7,11]$.

The parity distribution in the study population showed that $76.4 \%$ had parity $1-4$, followed with $16.7 \%$ grand multipara and the least $6.9 \%$ single/nulliparous women. With the mean age of the study population at $29.7( \pm 5.8$ ) years coupled with the depicted parity range of $0-14$, it suggests that the women are still at risk of large family size and unintended pregnancies with all their complications, reinforcing the need for modern family planning methods.

This study also showed that most (81.7\%) of the clients were educated up to secondary and tertiary levels reinforcing the observation that the frequency of contraceptive use increases with the level of education [12]. It was however gratifying to note from the records that majority $(63.1 \%)$ of the clients receiving family planning services at the center were counseled (Figure 3).

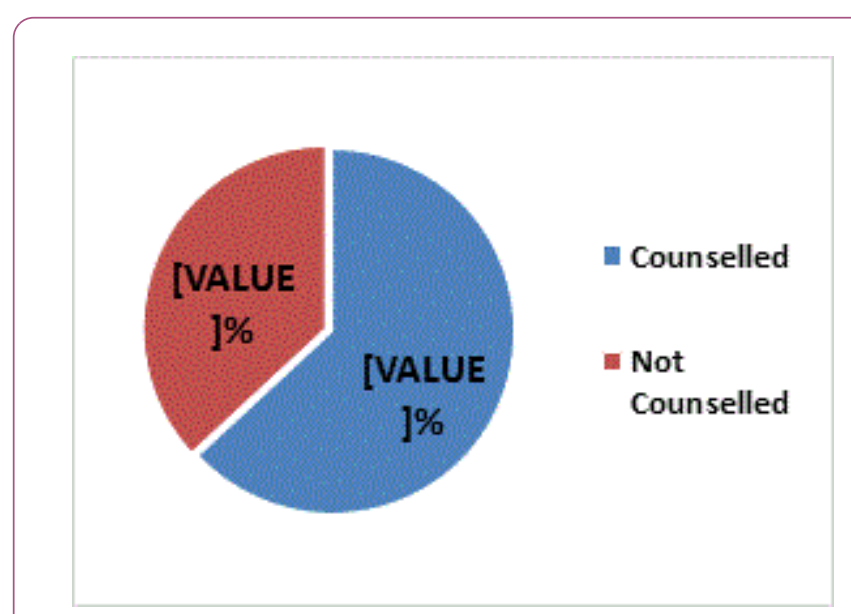

Figure 3 Distribution of Clients by counseling status.

Although it has been found in Nigeria that the most common methods of contraceptives in use include the pills, condoms, injectable and IUCDs [13], the most predominant 467 (57.9\%) contraceptive method chosen by clients in this study was the implant and the least was surgical sterilization by bilateral tubal ligation $1(0.1 \%)$. The finding of implant as the most preferred choice in this study is similar to the finding in Sokoto [7]. This however, contradicts the finding from many other centers in Nigeria where the IUCD (6) and the injectable contraceptives are the most frequent choices among clients 
$[4,14,15]$. The avoidance of the permanent surgical method of contraception is similar to the finding in other studies $[4,6,15]$. This is contrary to the finding in United Kingdom where BTL was $11.0 \%$ and vasectomy was $12.6 \%$ [15]. Condoms were the second most preferred method and this may be related to the advocacy for its use as not just a barrier contraceptive but a protection against HIV/AIDS transmission especially in our region.

\section{Conclusion}

In conclusion, the most preferred method of family planning in this study was the implant while the least was sterilization. It is also probable that the pattern of contraceptive use among the population especially the educated ones may have begun to shift towards the implant while still maintaining the use of condoms as a source of protection against HIV/AIDS and other sexually transmitted infections. With the observed rising trend in contraceptive use, there is the need to train personnel manning the family planning unit on the adequate counseling of clients on contraceptive choices and the opening of rural sites to towards improved utilization especially by adolescents and young people.

\section{References}

1. Monjok E, Smensy A, Ekabua JE, Esien EJ (2010) Contraceptive practices in Nigeria: literature review and recommendations for future policy decisions. Open Access J Contracept 1: 9-22.

2. Kalu AC, Umeora OU, Adeoye Si (2012) Experiences with provision of post-abortion care in a university teaching hospital in a South-East Nigeria: a five year review. Afr J Reprod Health 16: $105-112$.

3. National population commission and ICT Macro Nigeria Demographic and Health Survey (2008) Calverton, MD, USA.

4. Ameh N, Sule ST (2007) contraceptive choices among women in Zaria, Nigeria. Nigerian J Clin Practice 10: 205-207.
5. National Population Commission [Nigeria] and ICF International (2014) Nigeria Demographic and Health Survey. Rockville, Maryland, USA: National Population Commission and ICF International.

6. Adebara IO, ljaiya MA (2010) Recent trends in pattern of contraceptive usage at a Nigerian tertiary hospital. J Clin Med Res 2: 180-184.

7. Shehu CE, Burodo AT (2013) Contraceptive choices among women attending the fertility research unit of Usmanu Danfodiyo University Teaching Hospital, Sokoto. Sahel Med J 16: 93-96.

8. Egede JF, Onoh RC, Umeora J, lyoke CA, Dimejesi IBO, et al. (2015) Contraceptive prevalence and preference in a cohort of south-east Nigerian women. Patient Preference and Adherence 9: 707-714.

9. Nigerian Demographic and Health Survey 2013.

10. Nyengidiki KT, Eyindah CE (2008) Contraceptive prevalence among women attending infant welfare clinic at University of Port Harcourt Teaching Hospital. Port Harcourt Med J 3: 42-48.

11. Oye-Adeniran BA, Adewole IF, Umoh AV, Oladokun A, Gbadegesin A, et al. (2006) Community based study of contraceptive behavior in Nigeria. Afr J Reprod Health 10: 90-104.

12. Tuned-Ayinmode MF (2013) Current knowledge and pattern of use of family planning methods among a severely ill female psychiatric outpatients: implications for existing service. Ann Afr Med 12: 16-23.

13. Adeyemi AS, Adekanle DA, Komlafe JO (2008) Pattern of contraceptive choices among the married women attending the family planning clinic of a tertiary health institution. Nigerian J Med 17: 67-70.

14. Multihir J, Pam VC (2008) Overview of contraceptive use in Jos University Teaching Hospital, North Central Nigeria. Nigerian J Clin Practice 11: 139-143.

15. Glasier A. Contraception. In: Keith Edmonds D ed. Dewhurst's textbook of obstetrics and gynecology for postgraduates, (6th edn.), Blackwell Science, UK 373-392. 